\title{
Review Article \\ How to Achieve High-Quality Oocytes? The Key Role of Myo-Inositol and Melatonin
}

\author{
Salvatore Giovanni Vitale, ${ }^{1}$ Paola Rossetti, ${ }^{2}$ Francesco Corrado, \\ Agnese Maria Chiara Rapisarda, ${ }^{3}$ Sandro La Vignera, ${ }^{4}$ \\ Rosita Angela Condorelli, ${ }^{4}$ Gaetano Valenti, ${ }^{3}$ Fabrizio Sapia, ${ }^{3}$ \\ Antonio Simone Laganà, ${ }^{1}$ and Massimo Buscema ${ }^{2}$ \\ ${ }^{1}$ Unit of Gynecology and Obstetrics, Department of Human Pathology in Adulthood and Childhood "G. Barresi", \\ University of Messina, Messina, Italy \\ ${ }^{2}$ Unit of Diabetology and Endocrino-Metabolic Diseases, Hospital for Emergency Cannizzaro, Catania, Italy \\ ${ }^{3}$ Department of General Surgery and Medical Surgical Specialties, University of Catania, Catania, Italy \\ ${ }^{4}$ Department of Clinical and Experimental Medicine, Research Centre of Motor Activity and Metabolic Rehabilitation in Diabetes \\ (CRAMD), University of Catania, Catania, Italy
}

Correspondence should be addressed to Salvatore Giovanni Vitale; vitalesalvatore@hotmail.com

Received 30 June 2016; Accepted 2 August 2016

Academic Editor: John E. Nestler

Copyright (C) 2016 Salvatore Giovanni Vitale et al. This is an open access article distributed under the Creative Commons Attribution License, which permits unrestricted use, distribution, and reproduction in any medium, provided the original work is properly cited.

\begin{abstract}
Assisted reproductive technologies (ART) have experienced growing interest from infertile patients seeking to become pregnant. The quality of oocytes plays a pivotal role in determining ART outcomes. Although many authors have studied how supplementation therapy may affect this important parameter for both in vivo and in vitro models, data are not yet robust enough to support firm conclusions. Regarding this last point, in this review our objective has been to evaluate the state of the art regarding supplementation with melatonin and myo-inositol in order to improve oocyte quality during ART. On the one hand, the antioxidant effect of melatonin is well known as being useful during ovulation and oocyte incubation, two occasions with a high level of oxidative stress. On the other hand, myo-inositol is important in cellular structure and in cellular signaling pathways. Our analysis suggests that the use of these two molecules may significantly improve the quality of oocytes and the quality of embryos: melatonin seems to raise the fertilization rate, and myo-inositol improves the pregnancy rate, although all published studies do not fully agree with these conclusions. However, previous studies have demonstrated that cotreatment improves these results compared with melatonin alone or myo-inositol alone. We recommend that further studies be performed in order to confirm these positive outcomes in routine ART treatment.
\end{abstract}

\section{Introduction}

Female infertility, defined as a failure to achieve a successful pregnancy after 12 months or more of appropriate, timed unprotected intercourse or therapeutic donor insemination [1], has various causes and elements that play a key role including, aging, acute and chronic diseases, pharmacological therapies, behavioral factors, and exposure to environmental, occupational, and infectious agents. Data from 2006 to 2010 from the Center for Disease Control (CDC) National Survey of Family Growth show that, among all married
US women aged 15-44 years, 6\% (1.5 million women) were infertile and $12 \%$ (3.1 million women) had impaired fertility, defined as a condition in which there is physical difficulty in getting pregnant or carrying pregnancy to term [2]. These figures would be even more alarming if the data included statistics regarding couples who tried for one year or more to become pregnant and failed [3].

In recent decades, maternal age has progressively increased: in 1975 only $5 \%$ of women who became pregnant were over 30 years old, whereas in 2010 this percentage was $26 \%[4,5]$. Aging is one of the principal factors related to 
female fertility, with a direct correlation between increased maternal age and infertility/subfertility rates, probably due to diminished egg quality, ovulatory dysfunction, and reproductive disorders such as tubal diseases, leiomyoma, and endometriosis [6]. According to recent data, the fertility decline begins at the middle of third decade [7]. Reproductive outcomes depend directly on the quality of oocytes, which develop proper competence according to their genetic and epigenetic programming. The integrity of cytoskeleton, mitochondria function, and distribution play a pivotal role during the spindle formation and consequently modulate chromosomal segregation and maintain genome stability after division $[8,9]$. Spindle is composed of bundles of microtubules, which are polar polymers of $\alpha$ - and $\beta$ tubulin heterodimers. The most common defect in aging is shortening and disorganization of spindle, and this alteration may predispose the oocyte to aneuploidy or maturation arrest. In addition, mitochondria and endoplasmic reticulum control calcium-mediated intracellular signaling. This is of paramount importance for oocyte activation and modulates calcium/calmodulin-dependent protein kinase II, which is implicated in the transition from metaphase I to anaphase I [8].

Currently many infertile women undergo assisted reproductive technologies (ART) [10], dating from the first baby born after in vitro fertilization (IVF) and embryo transfer (ET) [11]. Thereafter, women affected by primary ovarian failure became pregnant with egg donation [12], a common procedure today [13]. Other techniques have been developed, such as gamete intrafallopian transfer (GIFT) and zygote intrafallopian transfer (ZIFT), although these are not universally applicable, for example, for women with tubal occlusion or in the case of male infertility [10]. ART has continued to grow with improvements in ultrasonography, including ultrasound-guided transvaginal follicular aspiration [14] with a consequent reduction in women's health risks and expenses. Intracytoplasmic sperm injection (ICSI) [15] was a step forward which improved outcome in the case of male infertility. Today IVF represents $99.5 \%$ of ART [13]. With growing interest in IVF as an answer to infertility, the interest of the scientific community is focused on supplementation, which can improve the outcome of these techniques.

\section{Rationale for the Use of Melatonin}

In recent years, attention has been focused on the negative impact of oxidative stress due to an excess of free radicals on oocyte quality during the IVF cycle. Free radicals are represented by reactive oxygen species (ROS), the most important class generated in living systems [16] and reactive nitrogen species (RNS). Free radicals play a dual role with both deleterious and beneficial effects. Physiologically free radicals maintain a balance in cells, called "redox balance" according to both its production and antioxidant cellular capacity. These are represented by both enzymatic antioxidant defenses, such as superoxide dismutase (SOD), glutathione peroxidase (GPx), catalase (CAT), and nonenzymatic antioxidant defenses, like ascorbic acid, $\alpha$-tocopherol, glutathione (GSH), carotenoids, flavonoids [17], and other molecules such as melatonin.

The overproduction of ROS results in oxidative stress, which can be an important mediator of damage to cell structures as lipids, membranes, proteins, and DNA [18]. On the other hand, free radicals are involved in cellular signaling pathways, in the induction of mitosis, and in defense against noxa as infectious agents. One physiological function in which ROS plays an fundamental role is reproductive physiology, including follicular development, oocyte maturation, ovulation, corpus luteum function, and follicular atresia [19]. Several authors compared ovulation to an inflammatory reaction with the production of cytokines and free radicals $[19,20]$. The follicular fluid (FF) obtained from antrum of Graafian follicles has a higher melatonin concentration than a plasma sample collected simultaneously [21]. This is probably related to the necessity to protect the oocyte from free radicals formed during oocyte maturation and to preserve oocyte quality [22]. As support, one study indicated that reduced antioxidant enzyme level was reported in the FF of women with unexplained infertility [23].

In 1993 it was discovered that melatonin is a potent endogenous scavenger of free radicals [24]. Before then melatonin was known as a hormone, produced by the pineal gland, with the ability to modulate circadian and reproductive physiology in photoperiod-dependent, seasonally breeding mammals [25]. Today it is known that melatonin links its receptors in the suprachiasmatic nuclei of the brain and in pars tuberalis in the pituitary gland to modulate the reproductive function. The presence of melatonin receptors is found in many other tissues of the reproductive system (epididymis, vas deferens, prostate, ovary, and mammary gland) [26] and other tissues including the skin, gastrointestinal tract, liver, kidney, spleen, and immune system cells. Enzymes involved in melatonin synthesis have been found in most of these tissues. These findings may relate to a hypothesis of multiple functions performed by melatonin (antioxidant, anti-inflammatory properties, genomic stabilizing effects, and modulator of mitochondrial homeostasis) [27].

Melatonin acts directly as a scavenging free radical [28] or in binding with its receptors [29] to prevent damage in cells and tissues. The antioxidant melatonin mechanism is different from other antioxidants because, after reacting with free radicals in a "scavenging cascade reaction," it generates several stable antioxidant end-products. It does not promote oxidation under any circumstances as this would terminate its properties as an antioxidant. In addition, melatonin synergizes with other nonenzymatic antioxidants [30] and also stimulates antioxidant enzyme synthesis by binding its membrane receptors to cytosolic or nuclear-binding sites [31].

Tamura et al. [32] measured melatonin concentration in FF in humans during oocyte retrieval for IVF-ET and correlated it with levels of 8-hydroxy-2-deoxyguanosine (8$\mathrm{OHdG}$ ), which is a product of free radical damage. They found an inverse correlation between two molecules, suggesting that $8-\mathrm{OHdG}$ is an index of degeneration of oocytes. Furthermore, the inverse relation between melatonin and 8OHdG may confirm the protective role of melatonin against oxidative stress [32]. In line with this last finding, a recent 
study [33] showed that mature follicles have a higher level of melatonin compared to immature follicles and that melatonin is secreted from luteinizing granulosa cells (GC). The study measured mRNA of enzymes involved in melatonin synthesis and found increased levels of mRNA in GC, which were able to be synthesized by this hormone. Based on these data, it is possible to speculate that melatonin may be released from luteinizing GC during late folliculogenesis and is involved in oocyte maturation.

During IVF, oocyte and embryos may be exposed to high levels of superoxide free radicals started during the stimulation protocol, in which oocyte manipulation alters the level of endogenous oxygen scavengers [34]. FF rich in antioxidants is absent in oocyte medium cultures including melatonin, which protects oocyte from oxidative stress. Furthermore the ROS level is higher during IVF due to a high oxygen concentration level in incubators and handing throughout the IVF process [35]. With the increase in "oxidative stress" during IVF, melatonin, with its scavenger properties, finds its proper use.

\section{Use of Melatonin in ART}

It was observed that adding melatonin in mouse oocyte cultures resulted in $54 \%$ of fertilized oocytes that reached the blastocyst stage compared to $29 \%$ without melatonin [36]. Other authors studied porcine oocytes cultures and found that adding melatonin to oocyte culture media produced a significantly lower level of ROS and a greater proportion of mature oocytes (MII) [37]. Recent evidence suggests that a concentration of melatonin in oocyte culture should be in a narrow range between $10^{-6}$ and $10^{-9} \mathrm{nM}$ to achieve the best results.

Some authors found that in humans supplementation with a low dose of melatonin improved oocyte nuclear maturation, and conversely decreased nuclear maturation was observed with a high dose [38]. A range from $10^{-5}$ to $10^{-9} \mathrm{nM}$ improved oocyte maturation when added at in vitro oocyte maturation (IVM), and it augmented the implantation rate during IVF-ET, increasing the pregnancy rate in women with PCOS, although in some cases the increase was not significant [33].

Tamura et al. [32], in addition, showed that oral administration of melatonin raised the concentration of melatonin in FF, and this higher concentration was inversely related to cellular oxidative stress measured by the 8 -OHdG level. In particular, they studied patients who had undergone unsuccessful IVF, dividing patients into two groups: the first treated with orally administered melatonin $(3 \mathrm{mg} /$ day) and the second without therapy. Considering their data analysis, they found that the first group had a higher fertilization rate than second group.

Other studies show that melatonin significantly improved morphologically MII during IVF compared to patients not treated. In contrast to Tamura et al.s data [32], these studies did not find an increased fertilization rate, although the number of class 1 embryos was higher in the treated group $[39,40]$, and pregnancy rates were higher in the treated group although the difference did not reach statistical significance [39].

Other authors showed that the fertilization rate improved with melatonin supplementation both in those with a lower fertilization rate during a previous IVF cycle and in those who underwent an ICSI procedure [41]. For a complete summary of the studies reported in this chapter, refer to Table 1.

\section{Rationale for the Use of Myo-Inositol}

Inositols are multifaceted molecules that play a fundamental role in many cellular functions. Myo-inositol (MI) and Dchiro-inositol (DCI) are two stereoisomers of a six-carbon cyclitol ring, and MI is a precursor of DCI and is most widely distributed in nature. Inositol is assumed to be an essential B complex vitamin with its main source being a normal diet, although it can be synthetized in the human. Inositols may be present in cells in different ways: incorporated in membrane phospholipids as phosphoinositides [42] and in the form of inositol phosphoglycans (IPG) located in the cytoplasmic membrane, which are involved in insulin transduction signaling as secondary messengers [43]. The role of phosphoinositides has long been known. They are fundamental elements of the cellular membrane, where inositol combines with cytidine diphosphate diacylglycerol to form phosphatidylinositol (PtdIns), a fundamental constituent of cell membranes. Inositol is involved in the phosphoinositides signaling pathway and plays a major role in numerous cellular functions [42]: phosphatidylinositol 4P (PtlIns-4P) and phosphatidylinositol 4,5 bisphosphate (PtdIns 4,5P) are the most studied. Two important second intracellular messengers, diacylglycerol (DAG) and inositoltriphosphate (Ins 1,4,5-P), are produced from PtdIns 4,5P. Ins 1,4,5-P binds $\mathrm{Ca} 2+$ channels in the rough endoplasmic reticulum stimulating intracellular $\mathrm{Ca} 2+$ release and, subsequently, numerous related intracellular effects. The increase in intracellular Ca2+ levels plays an important role in oocyte maturation, fertilization, and embryo development [4446]. Intracellular calcium-release mechanisms are modulated during the oocyte maturation process, particularly during the final stages of oocyte maturation. A major sensitivity to calcium release was observed in the final stage [47].

For all these reason, MI is involved in phosphoinositides pathway signaling and plays a key role in oocyte fertilization: many studies describe the relationship of its concentration level in FF, oocyte quality, and estrogen level in FF both in in vitro mouse models and in humans during IVF procedures $[48,49]$.

PtdIns 4,5P is involved in the development of cytoskeleton (CSK) and is involved in the binding between actin and the cellular membrane [42], suggesting a protective function for nuclear chromatin [50]. Another member of PtdIns molecules, PtdIns 3,4,5P, is involved in nuclear modulation of transcriptosome [51]. Some authors speculate that the depletion of inositol may desensitize the PtdIns pathway by slowing down resynthesis of a precursor [52].

Another important aspect of inositols is their role as insulin-sensitizers. In the form of IPG, they are able to 
TABLE 1: Effects of melatonin supplementation therapy (adding in oocytes culture or orally administered to patients) during ART.

\begin{tabular}{|c|c|c|c|c|c|c|}
\hline Authors & Species & $\begin{array}{l}\text { Melatonin } \\
\text { in vitro/in vivo }\end{array}$ & Patients number (tot) & $\begin{array}{c}\text { Intervention/control } \\
\text { number }\end{array}$ & Technique & $\begin{array}{l}\text { Significant outcomes } \\
\quad(p<0.05)\end{array}$ \\
\hline Lord et al. 2013 [36] & Mouse & $\begin{array}{l}\text { Adding } \mathrm{M} \text { in oocyte } \\
\text { culture medium }\end{array}$ & & & & $\begin{array}{l}\text { (i) Increased number } \\
\text { of oocytes that } \\
\text { reached blastocyst } \\
\text { stage }\end{array}$ \\
\hline Kang et al. 2009 [37] & Porcine & $\begin{array}{l}\text { Adding } \mathrm{M} \text { in oocyte } \\
\text { culture medium }\end{array}$ & & & & $\begin{array}{c}\text { (i) Increased mature } \\
\text { oocyte }\end{array}$ \\
\hline \multirow[b]{2}{*}{$\begin{array}{l}\text { Tamura et al. } 2008 \\
\text { [32] }\end{array}$} & & $\begin{array}{l}\text { Orally administered } \\
\text { M (3 mg/day) }\end{array}$ & 115 & $\begin{array}{c}56 \text { versus } 56 \\
\text { nontreated } 1^{\circ} \text { cycle } \\
\text { versus treated } 2^{\circ} \text { cycle }\end{array}$ & \multirow[b]{2}{*}{ IVF-ET } & $\begin{array}{l}\text { (i) Improved } \\
\text { fertilization rate }\end{array}$ \\
\hline & Human & $\begin{array}{l}\mathrm{M}(3 \mathrm{mg} / \text { day }) \text { versus } \\
\text { Vit. } \mathrm{E}(600 \mathrm{mg} / \text { day }) \\
\text { versus } \mathrm{M}+\mathrm{Vit} . \mathrm{E} \\
(3 \mathrm{mg}+600 \mathrm{mg} / \text { day })\end{array}$ & 18 & $\begin{array}{c}59 \text { versus } 59 \\
\text { nontreated } 1^{\circ} \text { cycle } \\
\text { versus nontreated } 2^{\circ} \\
\text { cycle }\end{array}$ & & $\begin{array}{c}\text { (i) Reduced 8-OHdG } \\
\text { in FF } \\
\text { (ii) Increased in FF in } \\
\text { treated patient. }\end{array}$ \\
\hline Kim et al. 2013 [33] & Human & $\begin{array}{l}\text { Adding } \mathrm{M} \text { in oocyte } \\
\text { culture medium }\end{array}$ & 111 & $62 / 49$ & $\begin{array}{l}\text { IVM } \\
\text { IVF-ET }\end{array}$ & $\begin{array}{l}\text { (i) Increased mature } \\
\text { oocyte } \\
\text { (ii) Increased } \\
\text { implantation }\end{array}$ \\
\hline $\begin{array}{l}\text { Batioglu et al. } 2012 \\
\text { [39] }\end{array}$ & Human & $\begin{array}{l}\text { Orally administered } \\
\text { M (3 mg/day) }\end{array}$ & 85 & $40 / 45$ & IVF-ET & $\begin{array}{l}\text { (i) Increased mature } \\
\text { oocyte } \\
\text { (ii) Increased good } \\
\text { quality embryos } \\
\end{array}$ \\
\hline $\begin{array}{l}\text { Eryilmaz et al. } 2011 \\
{[40]}\end{array}$ & Human & $\begin{array}{l}\text { Orally administered } \\
\text { M (3 mg/day) }\end{array}$ & 60 & $30 / 30$ & IVF-ET & $\begin{array}{l}\text { (i) Increased mature } \\
\text { oocyte } \\
\text { (ii) Increased good } \\
\text { quality embryos }\end{array}$ \\
\hline $\begin{array}{l}\text { Nishihara et al. } 2014 \\
\text { [41] }\end{array}$ & Human & $\begin{array}{l}\text { Orally administered } \\
\text { M (3 mg/day) }\end{array}$ & 97 & $\begin{array}{c}97 / 97 \\
\text { (control of itself) }\end{array}$ & $\begin{array}{l}\text { IVF } \\
\text { ICSI }\end{array}$ & $\begin{array}{l}\text { (i) Improved } \\
\text { fertilization with ICSI } \\
\text { (ii) Improved } \\
\text { fertilization in poor } \\
\text { responder } \\
\text { (iii) Improved good } \\
\text { quality embryos }\end{array}$ \\
\hline
\end{tabular}

M: melatonin; Vit. E: vitamin E; IVF: in vitro fertilization; ET: embryo transfer; IVM: in vitro maturation; ICSI: intracytoplasmic sperm injection; 8-OHdG: 8-hydroxy-2-deoxyguanosine.

activate insulin signaling pathways. IPG binds insulin with G-protein to create a coupled receptor to act as a secondary messenger, that is, DCI-phosphoglycan, which allows the activation of glycogen synthase both directly and indirectly via phosphatidylinositol 3-kinase (PIK3). It works to activate pyruvate dehydrogenase inside the mitochondria controlling oxidative glucose metabolism [53]. Conversely MIphosphoglycan, based on IPG, allows the inhibition of cyclic adenosine monophosphate (cAMP) kinase and adenylate cyclase that are a regulatory enzyme in free fatty acid (FFA) metabolism [54].

Previous data analysis [55] showed that the DCI level was $50 \%$ lower in muscle and urine samples derived from type II diabetic patients compared with samples from control subjects. Conversely MI did not differ between two groups studied. The imbalance between MI and DCI levels was called "inositol imbalance." The decline in DCI levels and inositol imbalance can be linked to insulin resistance (IR); and DCI levels worsened with the increase of insulin-resistance level $[56,57]$.
Many studies have shown that in patients with insulin resistance, such as in PCOS patients, using DCI, MI, and MI plus DCI may improve insulin resistance, metabolic parameters, regularity of cycle, and spontaneous ovulation [58-63] in keeping with insulin-sensitizer effects of DCI and the role of $\mathrm{MI}$ in oocytes maturation.

However a recent study confirmed that high DCI dosage (higher than $2.4 \mathrm{~g} /$ daily) had a negative effect on IVF outcome [64]. These data may explain the DCI ovary paradox theory in which insulin sensitivity remained in IR ovarian cells with a hyperstimulated epimerase function and with an imbalance between lower MI and higher DCI changing the physiologic $\mathrm{MI} / \mathrm{DCI}$ ratio [65].

\section{Use of Myo-Inositol in ART}

It has been suggested that MI added to in vitro culture media may increase bovine blastocyst development [66] just as MI improved in vitro maturation in mouse oocytes [67]. 
TABLE 2: Effects of myo-inositol supplementation therapy (adding in oocytes culture or orally administered to patients) during ART.

\begin{tabular}{|c|c|c|c|c|c|c|}
\hline Authors & Species & $\begin{array}{l}\text { Myo-inositol } \\
\text { in vitro/in vivo }\end{array}$ & Patients number (tot) & $\begin{array}{c}\text { Intervention/control } \\
\text { number }\end{array}$ & Technique & $\begin{array}{l}\text { Significant outcomes } \\
\qquad(p<0.05)\end{array}$ \\
\hline $\begin{array}{l}\text { Pesty et al. } 1994 \\
{[67]}\end{array}$ & Mouse & $\begin{array}{c}\text { Adding MI in oocyte } \\
\text { culture medium }\end{array}$ & & & & $\begin{array}{c}\text { (i) Improved oocyte } \\
\text { maturation }\end{array}$ \\
\hline $\begin{array}{l}\text { Chiu et al. } 2002 \\
\text { [48] }\end{array}$ & Human & $\begin{array}{l}\text { Adding MI in oocyte } \\
\text { culture medium }\end{array}$ & 53 & $32 / 21$ & IVF & $\begin{array}{l}\text { (i) Improved good } \\
\text { quality oocyte } \\
\text { (ii) Increased FF } \\
\text { volume }\end{array}$ \\
\hline
\end{tabular}

$\begin{array}{lcc} & \text { Orally administered } \\ \text { Brusco and } & \text { MI + FA }(2 \mathrm{~g}+ \\ \text { Mariani 2013 [68] } & \text { Human } & 400 \mathrm{mg} / \text { day }) \text { versus } \\ & & \text { FA (400 mg/day) }\end{array}$

Orally administered $\mathrm{MI}+\mathrm{FA}(2 \mathrm{~g}+$

Ciotta et al. 2011 Human $200 \mathrm{mg} /$ twice daily) [69]

\author{
versus FA \\ (400 mg/day)
}

(i) Improved number of good quality oocytes

(ii) Improved number embryos of grade $\mathrm{A}$

(iii) Increased clinical pregnancy rate

(i) Increased number oocytes retrieved

(ii) Increased numbers embryos transfer

(iii) Increased grade S1 embryos

(iv) Reduced number of immature oocytes

(i) Increased numbers mature oocyte

\begin{tabular}{|c|c|c|c|c|c|}
\hline $\begin{array}{l}\text { Unfer et al. } 2011 \\
\text { [71] }\end{array}$ & Human & $\begin{array}{c}\text { Orally administered } \\
\text { MI (2 g/twice daily) } \\
\text { versus DCI } \\
(0.6 \mathrm{~g} / \text { twice daily })\end{array}$ & 84 & $43 / 41$ & $\begin{array}{l}\text { IVF-ET } \\
\text { ICSI }\end{array}$ \\
\hline
\end{tabular}

(ii) Reduced number

of immature oocytes

(iii) Increased embryos grade 1

(i) Improved oocyte quality

(ii) Improved embryos quality (iii) Improved pregnancies rate

(i) Reduced number of immature oocytes

(ii) Decreased FSH unit and day of stimulation

(iii) Decreased E2

level before hCG stimulation

MI: myo-inositol; FA: folic acid; E2: estradiol; DCI: D-chiro-inositol; FF: follicular fluid; IVF: in vitro fertilization; ET: embryo transfer; ICSI: intracytoplasmic sperm injection; FSH: follicle stimulating hormone; hCG: human chorionic gonadotropin.

Chiu et al. [48] divided into two groups, according to oocytes quality, the oocytes retrieved from women treated with IVF: in group A they included good quality oocytes, whereas in group B they included bad quality oocytes. They showed that group A had significantly higher FF volume and higher MI level in FF without any difference in MI serum level between the two groups; MI was found to be higher in FF with oocytes that developed embryos with good morphology, with a positive correlation between MI level and fertilization rate. Also the estradiol level was higher in FF than in serum and was positively correlated with MI level in FF. Based on this evidence, a higher concentration of MI in FF could be due to the active transport of MI into FF as previously shown in an animal model [67]. These data suggest that $\mathrm{MI}$ is required to enhance the development of the maturing oocyte [48]. Other authors have shown that women under 40 years old with at least one of following features: a previous failed attempt with ICSI with low quality oocytes, or PCOS, or a diagnosis of "poor responders," treated with MI plus folic acid had higher number of good quality oocytes versus patients treated with only folic acid. The number of grade A embryos significantly increased the clinical pregnancy 
TABLE 3: Effects of myo-inositol + melatonin supplementation during ART.

\begin{tabular}{|c|c|c|c|c|c|c|}
\hline Authors & Species & $\begin{array}{l}\text { Myo-inositol + melatonin } \\
\text { in vitro/in vivo }\end{array}$ & $\begin{array}{l}\text { Patients number } \\
\text { (tot) }\end{array}$ & $\begin{array}{c}\text { Intervention/control } \\
\text { number }\end{array}$ & Technique & $\begin{array}{l}\text { Significant outcomes } \\
(p<0.05)\end{array}$ \\
\hline $\begin{array}{l}\text { Pacchiarotti et al. } \\
2016 \text { [73] }\end{array}$ & Human & $\begin{array}{c}\text { Orally administered MI } \\
\text { (4 g/day) }+ \text { FA } \\
(400 \text { mcg/day })+\mathrm{M} \\
\text { (3 g/day) versus MI } \\
\text { (4 g/day) }+ \text { FA } \\
\text { (400 mcg/day) versus FA } \\
\text { (400 mcg/day) }\end{array}$ & 526 & $165 / 166 / 195$ & $\begin{array}{c}\text { ICSI } \\
\text { IVF-ET }\end{array}$ & $\begin{array}{c}\text { (i) Increased mature } \\
\text { oocytes } \\
\text { (ii) Increased embryos } \\
\text { grade } 1 \\
\text { (iii) Reduced days of FSH } \\
\text { stimulation } \\
\text { (iv) Reduced E2 level } \\
\text { before hCG }\end{array}$ \\
\hline $\begin{array}{l}\text { Unfer et al. } 2011 \\
\text { [75] }\end{array}$ & Human & $\begin{array}{c}\text { Orally administered } \\
\text { MI ( } 4 \mathrm{~g} / \text { day })+\mathrm{FA} \\
(400 \mathrm{mcg} / \text { day })+\mathrm{M} \\
\text { (3 g/day) versus previous } \\
\text { failed IVF (themselves) }\end{array}$ & 46 & $46 / 46$ & IVF-ET & $\begin{array}{c}\text { (i) Increased mature } \\
\text { oocytes (MII) } \\
\text { (ii) Increased embryos } \\
\text { grade } 1 \\
\text { (iii) Reduced days and UI } \\
\text { of FSH stimulation }\end{array}$ \\
\hline $\begin{array}{l}\text { Rizzo et al. } 2010 \\
\text { [74] }\end{array}$ & Human & $\begin{array}{c}\text { Orally administered MI } \\
\text { (4 g/day) + FA } \\
(400 \mathrm{mcg} / \text { day })+\mathrm{M} \\
\text { (3 g/day) versus MI } \\
\text { (4 g/day) + FA } \\
\text { (400 mcg/day) }\end{array}$ & 65 & $32 / 33$ & & $\begin{array}{l}\text { (i) Increased mature } \\
\text { oocytes (MII) } \\
\text { (ii) Increased embryos } \\
\text { grade } 1-2\end{array}$ \\
\hline
\end{tabular}

MI: myo-inositol; FA: folic acid; M: melatonin; IVF: in vitro fertilization; ET: embryo transfer; ICSI: intracytoplasmic sperm injection; FSH: follicle stimulating hormone; hCG: human chorionic gonadotropin; UI: uterine insemination.

rate without reaching a significant difference if clinical and biochemical pregnancy rates are considered [68]. Another study confirmed the positive role of MI plus folic acid supplementation versus only folic acid in patients with PCOS, increasing the number of oocytes recovered and increasing the numbers of ET and good quality embryos while at the same time a reduction of immature oocytes was observed [69, 70]. MI used in women with PCOS caused a reduction in the total number of units and number of days of FSH stimulation, reducing estradiol (E2) levels measured the day before human chorionic gonadotropin (hCG) administration, allowing a decreased risk of hyperstimulation syndrome [70]. Other authors compared MI with DCI in patients, finding that MI had the capacity to ameliorate the quality of oocytes, to decrease the number of immature oocytes, and to improve the number of good quality embryos and the total number of pregnancies compared to DCI treatment during an ovarian stimulation protocol [71]. Other authors [72] found that MI plus DCI improved the quality of oocytes and the quality of embryos, reducing immature oocytes compared to only DCI treatment both in women under and over 35 years old. In patients under 35 years old, MI plus DCI also improved the fertilization rate. These authors speculated that MI plus DCI together can more quickly improve "inositol imbalance" and that DCI alone should be avoided in the IVF technique. For a complete summary of the studies reported in this chapter, refer to Table 2.

\section{Myo-Inositol and Melatonin in ART}

Recently many authors have investigated whether supplementation with MI and melatonin (plus folic acid), administered together, improved the PCOS outcome in IVF. These data suggested a synergistic effect with both MI and melatonin, which were able to improve the number of MII and the number of grade I embryos (good quality) compared to MI alone [73, 74]. Furthermore, MI and melatonin reduced significantly the units of gonadotropin used for stimulation as well as the E2 level reached before hCG injection. There was no significant increase in pregnancy rates in the study group with respect to controls [73], although others [74] found that both the fertilization rate and the pregnancy rate tended to be higher in the group cotreated with melatonin. Based on these data, it is possible to speculate that the positive effect of melatonin as ROS scavengers and its effect on the increase in LH receptors and progesterone synthesis bound its receptor in granulosa-luteal cells resulting in luteinization and ovulation. MI also plays a crucial role in oocyte maturation and as an insulin-sensitizer molecule. These features of MI and melatonin lead to a positive effect on oocyte and embryo quality in IVF [73]. In addition, therapy with MI plus $M$ in patients who failed to conceive in previous IVF cycles due to poor oocyte quality has been shown to improve oocytes and embryo quality during second IVF cycle, with a tendency toward augmented pregnancy rates, although it did not reach statistical significance in a large-cohort analysis [75]. For a complete summary of the studies reported in this chapter, refer to Table 3.

\section{Conclusion}

Melatonin is an oxidative scavenger and has an important role in the reduction of oxidative stress which physiologically increases during ovulation. This effect becomes more 
important during IVF. The manipulation of oocytes, incubated with high oxygen levels, increases the oxidative stress. Studies in vitro and in vivo have shown that melatonin improved oocyte quality and embryo quality. Some studies have shown an increased fertilization rate, and in one study it increased the implantation rate. The pregnancy rate tended to increase, although it was not statistically significant. As expected, melatonin treatment increased the melatonin concentration in FF and reduced the oxidative stress in FF measured by the 8-OHdG level.

MI plays an important role in cytoskeleton and in chromatin stabilization, all necessary features for correct oocyte maturation. It plays an important role as a PtdIns precursor involved in the intracellular $\mathrm{Ca} 2+$ signaling pathway that has been shown to be fundamental to proper oocytes maturation. Furthermore inositols have an insulinsensitizer effect. According to our overview, MI improves oocyte and embryo quality in patients undergoing IVF and is able to reduce units and days of FSH stimulation and E2 levels before hCG administration, thus reducing the risk of hyperstimulation syndrome especially in patients with PCOS and thus increasing pregnancy rates.

Combined therapy with MI and melatonin increased the positive effects described previously on outcome of ART. Cotreated patients showed an improved number of good quality oocytes and embryos, with reduced FSH units and days of treatment during cycles IVF.

Although these results are positive, more studies in large populations are necessary to confirm the data and to support the use of this supplementation therapy routinely in ART.

\section{Competing Interests}

The authors have no proprietary, financial, professional, or other personal interests of any nature in any product, service, or company. The authors alone are responsible for the content and writing of the paper.

\section{References}

[1] Practice Committee of American Society for Reproductive Medicine, "Definitions of infertility and recurrent pregnancy loss: a committee opinion," Fertility and Sterility, vol. 99, no. 1, p. 63, 2013.

[2] A. Chandra, C. E. Copen, and E. H. Stephen, "Infertility and impaired fecundity in the United States, 1982-2010: data from the National Survey of Family growth," National Health Statistics Reports 67, National Center for Health Statistics, Hyattsville, Md, USA, 2013.

[3] M. E. Thoma, A. C. McLain, J. F. Louis et al., "Prevalence of infertility in the United States as estimated by the current duration approach and a traditional constructed approach," Fertility and Sterility, vol. 99, no. 5, pp. 1324-1331.e1, 2013.

[4] S. J. Ventura, "Trend and variation in first births to older women. United States 1970-86," Vital and Health Statistics, vol. 21, pp. 1-27, 1989.

[5] B. E. Hamilton, J. A. Martin, and S. J. Ventura, "Births: preliminary data for 2010," National Vital Statistics Reports, vol. 60, pp. 1-25, 2011.
[6] D. T. Baird, J. Collins, J. Egozcue et al., "Fertility and ageing," Human Reproduction Update, vol. 11, no. 3, pp. 261-276, 2005.

[7] J. Menken, J. Trussell, and U. Larsen, "Age and infertility," Science, vol. 233, no. 4771, pp. 1389-1394, 1986.

[8] D. T. Baird, J. Collins, J. Egozcue et al., "Fertility and ageing," Human Reproduction Update, vol. 11, no. 3, pp. 261-267, 2005.

[9] U. Eichenlaub-Ritter, E. Vogt, H. Yin, and R. Gosden, "Spindles, mitochondria and redox potential in ageing oocytes," Reproductive BioMedicine Online, vol. 8, no. 1, pp. 45-58, 2004.

[10] J. Wang and M. V. Sauer, "In vitro fertilization (IVF): a review of 3 decades of clinical innovation and technological advancement," Therapeutics and Clinical Risk Management, vol. 2, no. 4, pp. 355-364, 2006.

[11] P. C. Steptoe and R. G. Edwards, "Birth after the reimplantation of a human embryo," The Lancet, vol. 2, no. 8085, p. 366, 1978.

[12] P. Lutjen, A. Trounson, J. Leeton, J. Findlay, C. Wood, and P. Renou, "The establishment and maintenance of pregnancy using in vitro fertilization and embryo donation in a patient with primary ovarian failure," Nature, vol. 307, no. 5947, pp. 174175, 1984.

[13] CDC-National Center for Chronic Disease Prevention and Health Promotion, "Assisted reproductive technology success rates. National summary and fertility clinic reports (online)," http://www.cdc.gov/art/pdf/2013-report/art-2013-fertility-clinic-report.pdf.

[14] M. Wikland, L. Enk, K. Hammarberg, and L. Nilsson, "Use of a vaginal transducer for oocyte retrieval in an IVF/ET program," Journal of Clinical Ultrasound, vol. 15, no. 4, pp. 245-251, 1987.

[15] G. Palermo, H. Joris, P. Devroey, and A. C. Van Steirteghem, "Pregnancies after intracytoplasmic injection of single spermatozoon into an oocyte," The Lancet, vol. 340, no. 8810, pp. 17-18, 1992.

[16] D. M. Miller, G. R. Buettner, and S. D. Aust, "Transition metals as catalysts of 'autoxidation' reactions," Free Radical Biology and Medicine, vol. 8, no. 1, pp. 95-108, 1990.

[17] M. Valko, D. Leibfritz, J. Moncol, M. T. D. Cronin, M. Mazur, and J. Telser, "Free radicals and antioxidants in normal physiological functions and human disease," International Journal of Biochemistry and Cell Biology, vol. 39, no. 1, pp. 44-84, 2007.

[18] M. Valko, C. J. Rhodes, J. Moncol, M. Izakovic, and M. Mazur, "Free radicals, metals and antioxidants in oxidative stressinduced cancer," Chemico-Biological Interactions, vol. 160, no. 1, pp. 1-40, 2006.

[19] N. Sugino, "Reactive oxygen species in ovarian physiology," Reproductive Medicine and Biology, vol. 4, no. 1, pp. 31-44, 2005.

[20] L. L. Espey, "Ovulation as an inflammatory reaction: a hypothesis," Biology of Reproduction, vol. 22, no. 1, pp. 73-106, 1980.

[21] Y. Nakamura, H. Tamura, H. Takayama, and H. Kato, "Increased endogenous level of melatonin in preovulatory human follicles does not directly influence progesterone production," Fertility and Sterility, vol. 80, no. 4, pp. 1012-1016, 2003.

[22] H. Tamura, Y. Nakamura, A. Korkmaz et al., "Melatonin and the ovary: physiological and pathophysiological implications," Fertility and Sterility, vol. 92, no. 1, pp. 328-343, 2009.

[23] T. Paszkowski, A. I. Traub, S. Y. Robinson, and D. McMaster, "Selenium dependent glutathione peroxidase activity in human follicular fluid," Clinica Chimica Acta, vol. 236, no. 2, pp. 173180, 1995.

[24] D. X. Tan, L. D. Chen, B. Poeggeler, L. C. Manchester, and R. J. Reiter, "Melatonin: a potent, endogenous hydroxyl radical scavenger," Endocrine Journal, vol. 1, pp. 57-60, 1993. 
[25] R. J. Reiter and R. J. Hester, "Interrelationships of the pineal gland, the superior cervical ganglia and the photoperiod in the regulation of the endocrine systems of hamsters," Endocrinology, vol. 79, no. 6, pp. 1168-1170, 1966.

[26] S. F. Pang, L. Li, E. A. Ayre et al., "Neuroendocrinology of melatonin in reproduction: recent developments," Journal of Chemical Neuroanatomy, vol. 14, no. 3-4, pp. 157-166, 1998.

[27] D. Acuña-Castroviejo, G. Escames, C. Venegas et al., "Extrapineal melatonin: sources, regulation, and potential functions," Cellular and Molecular Life Sciences, vol. 71, no. 16, pp. 29973025, 2014.

[28] H. Tamura, A. Takasaki, T. Taketani et al., "The role of melatonin as an antioxidant in the follicle," Journal of Ovarian Research, vol. 26, article 5, 2012.

[29] M. L. Dubocovich and M. Markowska, "Functional $\mathrm{MT}_{1}$ and $\mathrm{MT}_{2}$ melatonin receptors in mammals," Endocrine, vol. 27, no. 2, pp. 101-110, 2005.

[30] D.-X. Tan, L. C. Manchester, R. J. Reiter, W.-B. Qi, M. Karbownik, and J. R. Calvo, "Significance of melatonin in antioxidative defense system: reactions and products," Biological Signals and Receptors, vol. 9, no. 3-4, pp. 137-159, 2000.

[31] C. Tomás-Zapico and A. Coto-Montes, "A proposed mechanism to explain the stimulatory effect of melatonin on antioxidative enzymes," Journal of Pineal Research, vol. 39, no. 2, pp. 99-104, 2005.

[32] H. Tamura, A. Takasaki, I. Miwa et al., "Oxidative stress impairs oocyte quality and melatonin protects oocytes from free radical damage and improves fertilization rate," Journal of Pineal Research, vol. 44, no. 3, pp. 280-287, 2008.

[33] M. K. Kim, E. A. Park, H. J. Kim et al., "Does supplementation of in-vitro culture medium with melatonin improve IVF outcome in PCOS?" Reproductive BioMedicine Online, vol. 26, no. 1, pp. 22-29, 2013.

[34] S. Palini, S. Benedetti, M. C. Tagliamonte et al., "Influence of ovarian stimulation for IVF/ICSI on the antioxidant defence system and relationship to outcome," Reproductive BioMedicine Online, vol. 29, no. 1, pp. 65-71, 2014.

[35] S. Fernando and L. Rombauts, "Melatonin: shedding light on infertility? A review of the recent literature," Journal of Ovarian Research, vol. 7, article 98, 2014.

[36] T. Lord, B. Nixon, K. T. Jones, and R. J. Aitken, "Melatonin prevents postovulatory oocyte aging in the mouse and extends the window for optimal fertilization in vitro," Biology of Reproduction, vol. 88, no. 3, article 67, 2013.

[37] J.-T. Kang, O.-J. Koo, D.-K. Kwon et al., "Effects of melatonin on in vitro maturation of porcine oocyte and expression of melatonin receptor RNA in cumulus and granulosa cells," Journal of Pineal Research, vol. 46, no. 1, pp. 22-28, 2009.

[38] D. Wei, C. Zhang, J. Xie et al., "Supplementation with low concentrations of melatonin improves nuclear maturation of human oocytes in vitro," Journal of Assisted Reproduction and Genetics, vol. 30, no. 7, pp. 933-938, 2013.

[39] A. S. Batioglu, U. U. Sahin, N. Ozturk, and E. Unsal, "The efficacy of melatonin administration on oocyte quality," Gynecological Endocrinology, vol. 28, pp. 91-93, 2012.

[40] O. G. Eryilmaz, A. Devran, E. Sarikaya, F. N. Aksakal, L. Mollamahmutoglu, and N. Cicek, "Melatonin improves the oocyte and the embryo in IVF patients with sleep disturbances, but does not improve the sleeping problems," Journal of Assisted Reproduction and Genetics, vol. 28, no. 9, pp. 815-820, 2011.
[41] T. Nishihara, S. Hashimoto, K. Ito et al., "Oral melatonin supplementation improves oocyte and embryo quality in women undergoing in vitro fertilization-embryo transfer," Gynecological Endocrinology, vol. 30, no. 5, pp. 359-362, 2014.

[42] G. Di Paolo and P. De Camilli, "Phosphoinositides in cell regulation and membrane dynamics," Nature, vol. 443, no. 7112, pp. 651-657, 2006.

[43] J. Larner, "D-chiro-inositol-its functional role in insulin action and its deficit in insulin resistance," International Journal of Experimental Diabetes Research, vol. 3, no. 1, pp. 47-60, 2002.

[44] P. T. Goud, A. P. Goud, L. Leybaert et al., "Inositol 1,4,5trisphosphate receptor function in human oocytes: calcium responses and oocyte activation-related phenomena induced by photolytic release of $\mathrm{InsP}_{3}$ are blocked by a specific antibody to the type I receptor," Molecular Human Reproduction, vol. 8, no. 10, pp. 912-918, 2002.

[45] L. M. Mehlmann and D. Kline, "Regulation of intracellular calcium in the mouse egg: calcium release in response to sperm or inositol trisphosphate is enhanced after meiotic maturation," Biology of Reproduction, vol. 51, no. 6, pp. 1088-1098, 1994.

[46] J. J. Stachecki and D. R. Armant, “Transient release of calcium from inositol 1,4,5-triphosphate specific store, regulates mouse preimplantation development," Development, vol. 122, pp. 24852496, 1996.

[47] J. Carroll, K. T. Jones, and D. G. Whittingham, " $\mathrm{Ca}^{2+}$ release and the development of $\mathrm{Ca}^{2+}$ release mechanisms during oocyte maturation: A prelude to fertilization," Reviews of Reproduction, vol. 1, no. 3, pp. 137-143, 1996.

[48] T. T. Y. Chiu, M. S. Rogers, E. L. K. Law, C. M. Briton-Jones, L. P. Cheung, and C. J. Haines, "Follicular fluid and serum concentrations of myo-inositol in patients undergoing IVF: relationship with oocyte quality," Human Reproduction, vol. 17, no. 6, pp. 1591-1596, 2002.

[49] T. T. Y. Chiu, M. S. Rogers, C. Briton-Jones, and C. Haines, "Effects of myo-inositol on the in-vitro maturation and subsequent development of mouse oocytes," Human Reproduction, vol. 18, no. 2, pp. 408-416, 2003.

[50] X. Shen, H. Xiao, R. Ranallo, W.-H. Wu, and C. Wu, "Modulation of ATP-dependent chromatin-remodeling complexes by inositol polyphosphates," Science, vol. 299, no. 5603, pp. 112-114, 2003.

[51] M. Falasca and T. Maffucci, "Rethinking phosphatidylinositol 3-monophosphate," Biochimica et Biophysica Acta-Molecular Cell Research, vol. 1793, no. 12, pp. 1795-1803, 2009.

[52] M. J. Berridge and R. F. Irvine, "Inositol phosphates and cell signalling," Nature, vol. 341, no. 6239, pp. 197-205, 1989.

[53] J. Larner, D. L. Brautigan, and M. O. Thorner, "D-chiro-inositol glycans in insulin signaling and insulin resistance," Molecular Medicine, vol. 16, no. 11-12, pp. 543-551, 2010.

[54] J. Larner, L. C. Huang, C. F. W. Schwartz et al., "Rat liver insulin mediator which stimulates pyruvate dehydrogenase phosphatase contains galactosamine and D-chiroinositol," Biochemical and Biophysical Research Communications, vol. 151, no. 3, pp. 1416-1426, 1988.

[55] I. Asplin, G. Galasko, and J. Larner, "chiro-Inositol deficiency and insulin resistance: a comparison of the chiro-inositol- and the myo-inositol-containing insulin mediators isolated from urine, hemodialysate, and muscle of control and type II diabetic subjects," Proceedings of the National Academy of Sciences of the United States of America, vol. 90, no. 13, pp. 5924-5928, 1993. 
[56] J. Larner and J. W. Craig, "Urinary myo-inositol-to-chiroinositol ratios and insulin resistance," Diabetes Care, vol. 19, no. 1, pp. 76-78, 1996.

[57] J.-P. Baillargeon, E. Diamanti-Kandarakis, R. E. Ostlund Jr., T. Apridonidze, M. J. Iuorno, and J. E. Nestler, "Altered D-chiroinositol urinary clearance in women with polycystic ovary syndrome," Diabetes Care, vol. 29, no. 2, pp. 300-305, 2006.

[58] J. E. Nestler, D. J. Jakubowicz, P. Reamer, R. D. Gunn, and G. Allan, "Ovulatory and metabolic effects of D-chiro-inositol in the polycystic ovary syndrome," The New England Journal of Medicine, vol. 340, no. 17, pp. 1314-1320, 1999.

[59] A. D. Genazzani, C. Lanzoni, F. Ricchieri, and V. M. Jasonni, "Myo-inositol administration positively affects hyperinsulinemia and hormonal parameters in overweight patients with polycystic ovary syndrome," Gynecological Endocrinology, vol. 24, no. 3, pp. 139-144, 2008.

[60] A. Pizzo, A. S. Laganà, and L. Barbaro, "Comparison between effects of myo-inositol and D-chiro-inositol on ovarian function and metabolic factors in women with PCOS," Gynecological Endocrinology, vol. 30, no. 3, pp. 205-208, 2014.

[61] S. Gerli, M. Mignosa, and G. C. Di Renzo, "Effects of inositol on ovarian function and metabolic factors in women with PCOS: a randomized double blind placebo-controlled trial," European Review for Medical and Pharmacological Sciences, vol. 7, no. 6, pp. 151-159, 2003.

[62] C. Paul, A. S. Laganà, P. Maniglio, O. Triolo, and D. M. Brady, "Inositol's and other nutraceuticals' synergistic actions counteract insulin resistance in polycystic ovarian syndrome and metabolic syndrome: state-of-the-art and future perspectives," Gynecological Endocrinology, vol. 32, no. 6, pp. 431-438, 2016.

[63] M. Nordio and E. Proietti, "The combined therapy with myoinositol and D-Chiro-inositol reduces the risk of metabolic disease in PCOS overweight patients compared to myo-inositol supplementation alone," European Review for Medical and Pharmacological Sciences, vol. 16, no. 5, pp. 575-581, 2012.

[64] R. Isabella and E. Raffone, "Does ovary need D-chiro-inositol?" Journal of Ovarian Research, vol. 5, no. 1, article 14, 2012.

[65] G. Carlomagno, V. Unfer, and S. Roseff, "The D-chiro-inositol paradox in the ovary," Fertility and Sterility, vol. 95, no. 8, pp. 2515-2516, 2011.

[66] P. Holm, P. J. Booth, M. H. Schmidt, T. Greve, and H. Callesen, "High bovine blastocyst development in a static in vitro production system using SOFaa medium supplemented with sodium citrate and myo-inositol with or without serumproteins," Theriogenology, vol. 52, no. 4, pp. 683-700, 1999.

[67] A. Pesty, B. Lefevre, J. Kubiak, G. Geraud, J. Tesarik, and B. Maro, "Mouse oocyte maturation is affected by lithium via the polyphosphoinositide metabolism and the microtubule network," Molecular Reproduction and Development, vol. 38, no. 2, pp. 187-199, 1994.

[68] G. F. Brusco and M. Mariani, "Inositol: effects on oocyte quality in patients undergoing ICSI. An open study," European Review for Medical and Pharmacological Sciences, vol. 17, no. 22, pp. 3095-3102, 2013.

[69] L. Ciotta, M. Stracquadanio, I. Pagano, A. Carbonaro, M. Palumbo, and F. Gulino, "Effects of myo-inositol supplementation on oocyte's quality in PCOS patients: a double blind trial," European Review for Medical and Pharmacological Sciences, vol. 15, no. 5, pp. 509-514, 2011.

[70] E. Papaleo, V. Unfer, J.-P. Baillargeon, F. Fusi, F. Occhi, and L. De Santis, "Myo-inositol may improve oocyte quality in intracytoplasmic sperm injection cycles. A prospective, controlled, randomized trial," Fertility and Sterility, vol. 91, no. 5, pp. 1750$1754,2009$.

[71] V. Unfer, G. Carlomagno, P. Rizzo, E. Raffone, and S. Roseff, "Myo-inositol rather than D-chiro-inositol is able to improve oocyte quality in intracytoplasmic sperm injection cycles. A prospective, controlled, randomized trial," European Review for Medical and Pharmacological Sciences, vol. 15, no. 4, pp. 452-457, 2011.

[72] S. Colazingari, M. Treglia, R. Najjar, and A. Bevilacqua, "The combined therapy myo-inositol plus D-chiro-inositol, rather than D-chiro-inositol, is able to improve IVF outcomes: results from a randomized controlled trial," Archives of Gynecology and Obstetrics, vol. 288, no. 6, pp. 1405-1411, 2013.

[73] A. Pacchiarotti, G. Carlomagno, G. Antonini, and A. Pacchiarotti, "Effect of myo-inositol and melatonin versus myoinositol, in a randomized controlled trial, for improving in vitro fertilization of patients with polycystic ovarian syndrome," Gynecological Endocrinology, vol. 32, no. 1, pp. 69-73, 2016.

[74] P. Rizzo, E. Raffone, and V. Benedetto, "Effect of the treatment with myo-inositol plus folic acid plus melatonin in comparison with a treatment with myo-inositol plus folic acid on oocyte quality and pregnancy outcome in IVF cycles. A prospective, clinical trial," European Review for Medical and Pharmacological Sciences, vol. 14, no. 6, pp. 555-561, 2010.

[75] V. Unfer, E. Raffone, P. Rizzo, and S. Buffo, "Effect of a supplementation with myo-inositol plus melatonin on oocyte quality in women who failed to conceive in previous in vitro fertilization cycles for poor oocyte quality: a prospective, longitudinal, cohort study," Gynecological Endocrinology, vol. 27, no. 11, pp. 857-861, 2011. 


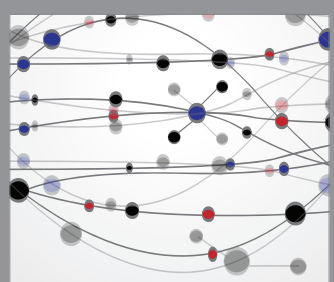

The Scientific World Journal
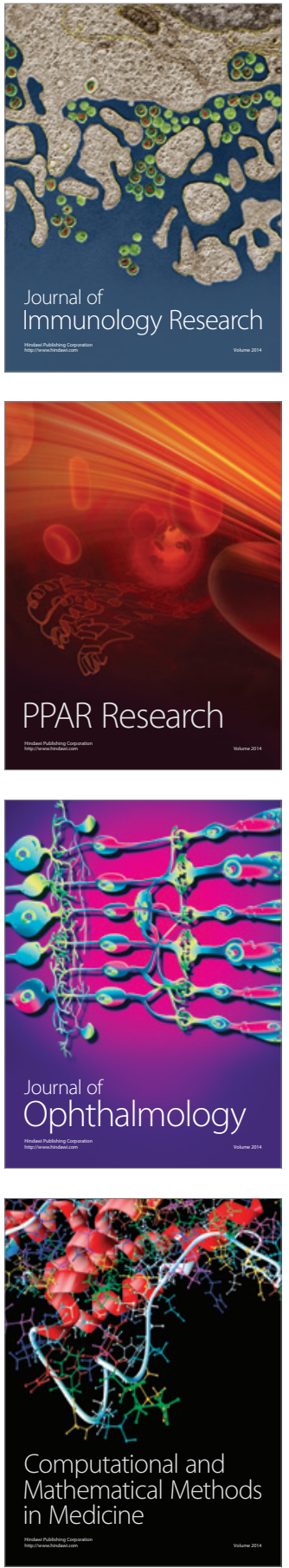

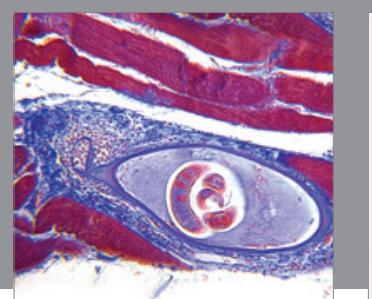

Gastroenterology Research and Practice

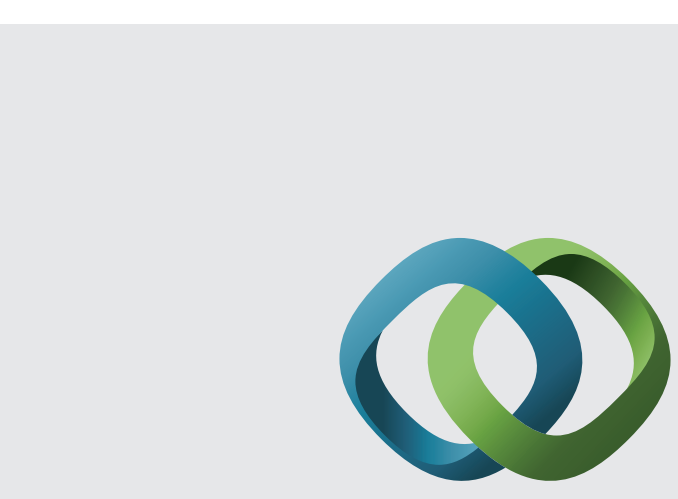

\section{Hindawi}

Submit your manuscripts at

http://www.hindawi.com
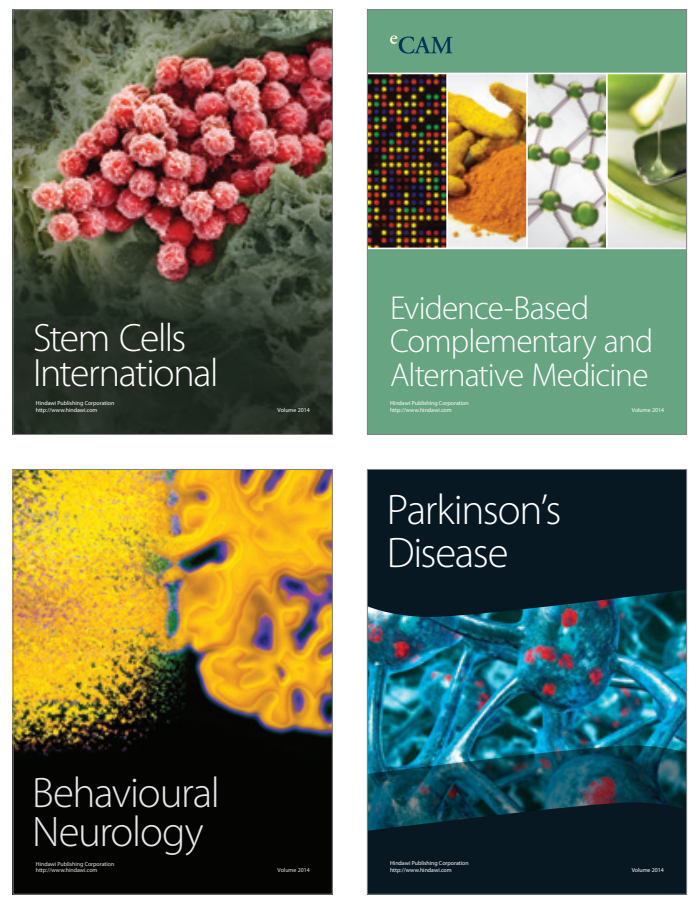
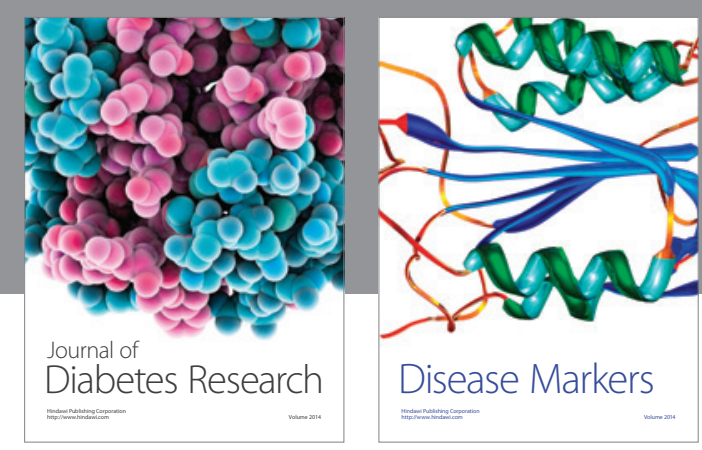

Disease Markers
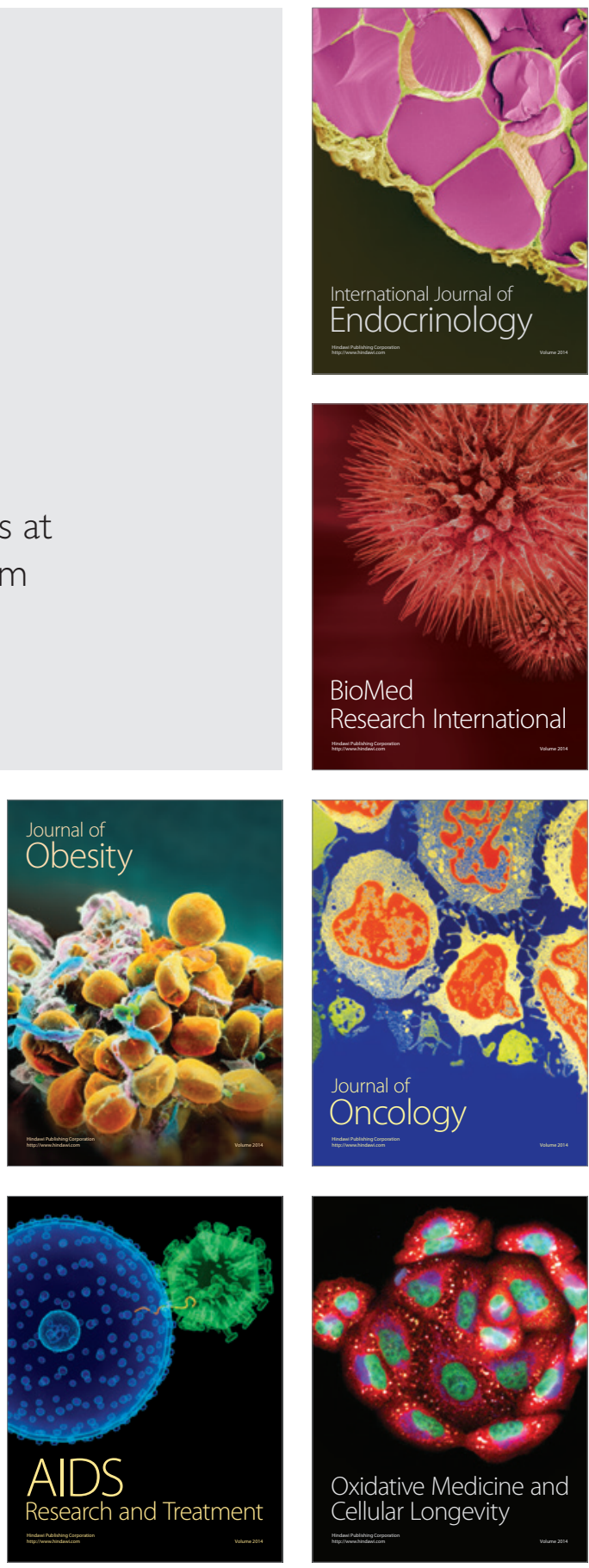